\title{
Flash visual evoked potential monitoring of optic tract function during macroelectrode-based pallidotomy
}

\section{Eugene A. Bonaroti, M.D., Robert D. Rose, Ph.D., Douglas Kondziolka, M.D., Susan Baser, M.D.,} and L. Dade Lunsford, M.D.

Department of Neurological Surgery, University of Pittsburgh School of Medicine, Pittsburgh, Pennsylvania

Posteroventral pallidotomy (PVP) has received renewed interest as an ablative procedure for the symptomatic treatment of Parkinson's disease. In previous reports, the proximity of the optic tract to the lesion target in the globus pallidus internus has resulted in the occurrence of visual field deficits in as much as $14 \%$ of patients. The authors have used intraoperative visual evoked potentials (VEPs) during PVP to reduce this risk. All procedures were performed in awake patients. Flash stimuli were delivered to each eye via fiberoptic sources. Baseline flash VEPs were recorded at $\mathrm{O} 1 / \mathrm{Cz}$ (left visual cortex to vertex), $\mathrm{Oz} / \mathrm{Cz}$ (midline visual cortex to vertex), and $\mathrm{O} 2 / \mathrm{Cz}$ (right visual cortex to vertex) for $\mathrm{OS}, \mathrm{OU}$, and OD stimulation. Epochs were acquired before and after localization, after macroelectrode stimulation, after temporary thermal lesioning, and after permanent thermal lesioning. Forty-seven patients underwent a total of 59 procedures. Visual evoked potentials were recorded reproducibly in all patients. In 11 procedures, VEP changes were reported, including six amplitude changes (10-80\%), six latency shifts $(3-10 \mathrm{msec})$, and one report of "variability." In four procedures, VEP changes prompted a change in target coordinates. One false-positive and one false-negative VEP change were encountered. The only confirmed visual deficit was a superior quadrantanopsia, present on formal fields, but clinically asymptomatic. The authors conclude that VEPs may be useful for procedures performed in the awake patient because of the lack of anesthetic-induced variability. The $1.7 \%$ visual morbidity reported here (one in 59 patients) compares favorably with other series using microelectrodes. Visual evoked potentials may be a useful monitoring technique to reduce the incidence of clinically significant visual morbidity during pallidotomy, especially during formal lesioning of the ventral pallidum adjacent to the optic tract.

Key Words * visual evoked potentials * pallidotomy * Parkinson's disease * intraoperative monitoring

Posteroventral pallidotomy (PVP) is currently advocated for the treatment of symptomatic advanced Parkinson's disease (PD).[14] Studies using macroelectrode techniques,[21] microelectrode techniques,[4,11,23] or a combination of both,[17] have shown that PVP may improve all three cardinal manifestations of PD: rigidity, bradykinesia, and tremor. Statistically significant improvements have been documented in Unified Parkinson's Disease Rating Scale (UPDRS) scores, an objective measure of motor performance in patients who have undergone PVP.[4,11,17] 
The proximity of the optic tract to the ablative target, the globus pallidus internus (GPi), accounts for the association of PVP with postoperative visual field deficits. Previous studies have reported visual morbidity between $0 \%$ and $14 \% .[4,11,17,21,23]$ These prior reports have not used intraoperative cortical visual evoked potential (VEP) monitoring. During microelectrode-monitored pallidotomy Lozano, et al.,[22] have described the use of directly recorded potentials in the optic nerve evoked by flash stimulus.

Visual evoked potential monitoring has been described by several groups as helpful in assessing the status of the visual pathways during surgery.[1,10,12,16,28,30-32] In contrast, other investigators have concluded that intraoperative flash VEPs are unreliable.[2,8,15,25] Previous problems with intraoperative VEPs in other settings have often stemmed from unacceptable anesthetic-induced variability[13] unrelated to actual optic pathway injury. In this pilot study, we have used VEPs to minimize visual morbidity in awake patients undergoing PVP.

\section{CLINICAL MATERIAL AND METHODS}

\section{Patient Selection}

All patients in whom pallidotomy was performed at the University of Pittsburgh Medical Center between April 1993 and April 1996 are included in this study. Patients with unilateral or bilateral rigidity and/or bradykinesia due to idiopathic PD were offered pallidotomy. The presence of levodopa-induced dyskinesias was also an indication for surgery. Patients with predominantly unilateral tremor were offered thalamotomy. Prior to surgery, medical therapy was maximized, usually with multiple agents. The majority of patients were evaluated pre- and postoperatively by a neurologist specializing in movement disorders (S.B.). The presence of a preexisting visual field deficit was an exclusion criterion. Other exclusion criteria were coagulopathy, uncontrolled hypertension, age older than 85 years, and patients with "Parkinson's plus" syndromes.[18]

The study group included 30 men and 17 women. The mean age was 66.1 years \pm 8.1 standard deviation (SD), the average duration of illness was 13.8 years $\pm 6.3 \mathrm{SD}$, and the median preoperative Hoehn and Yahr score was 4 (range 2.5-5).

\section{Pallidotomy Technique}

A macroelectrode technique was used and has been described elsewhere.[18] Throughout PVP patients were awake and cooperative; a mild anxiolytic or narcotic agent was used sparingly. Gadolinium-enhanced magnetic resonance (MR) imaging was performed using a $\mathrm{T}_{1}$-weighted sagittal localizing sequence, a volume acquisition fast gradient echo, and a fast inversion recovery sequence in both the coronal and axial planes. A radiofrequency probe (Radionics, Inc., Burlington, MA) with a 1.1-mm diameter and 3-mm exposed tip was used for both stimulation and lesion production. Initial targets were based on the coordinates described by Laitinen, et al.:[21] 2 to $3 \mathrm{~mm}$ anterior to the anterior commissure-posterior commissure midpoint, 18 to $22 \mathrm{~mm}$ lateral, and 5 to $6 \mathrm{~mm}$ inferior. Initial lateral coordinates varied for women $(19 \mathrm{~mm})$ and men $(21 \mathrm{~mm})$. Lateral coordinates were increased in patients in whom the third ventricle was dilated more than $4 \mathrm{~mm}$. Targets were modified based on imaging that relied heavily on the coronal inversion recovery images. Targets that encroached on the optic nerve were moved superiorly, whereas those that encroached on the internal capsule were moved laterally. The GPi and GP externus (GPe) were typically well visualized on the coronal inversion recovery sequence, and targets were moved medially out of GPe and into GPi in several patients. 
Motor, speech, and cognitive function were monitored clinically throughout the procedure.

Macroelectrode stimulation was performed at 0.5 to $3 \mathrm{~V}$ and 5, 50, and $100 \mathrm{~Hz}$. Target adjustment was indicated if any of the following occurred at thresholds of $2 \mathrm{~V}$ or less: visual symptoms, VEP changes, contralateral limb weakness or hypotonia, or a "capsular response" (marked rigidity and dysarthria or speech arrest). Also, if the patient's rigidity, tremor, or dyskinesia could not be modulated at all by stimulation, the target was moved. Test lesions (temporary thermal lesions) were performed at 40šC for 30 seconds. Permanent lesions were made at 70 to 78 šC for 60 seconds. (The slight variability in temperature relates to the manual feedback control of the radiofrequency generator thermocouple.)

\section{Visual Evoked Potentials}

Preoperative baseline flash VEPs used a light source positioned $100 \mathrm{~cm}$ from the patient's nasion for monocular and binocular stimulation. Intraoperatively, flash stimuli were delivered through closed eyelids via fiberoptic light sources with attached reflective shields. Ambient light was minimized and maintained constant during recording. Intraoperative baseline flash VEPs were recorded while the patient was on the operating table using 128 trials per epoch at a stimulus frequency of $1.1 \mathrm{~Hz}$, a 200 to 400-msec observation interval, an amplifier bandwidth of 1 to $300 \mathrm{~Hz}$, and a gain of 10 to $50 \mathrm{k}$. Recordings were made from $\mathrm{O} 1 / \mathrm{Cz}$ (left visual cortex to vertex), $\mathrm{Oz} / \mathrm{Cz}$ (midline visual cortex to vertex), and $\mathrm{O} 2 / \mathrm{Cz}$ (right visual cortex to vertex).

For intraoperative recording, monocular stimulation was used exclusively, usually alternating epochs between the ipsilateral and contralateral eyes. Epochs were acquired immediately before and after GPi localization, GPi stimulation, test thermal lesioning, and permanent GPi lesions. Patients were questioned regarding visual phenomena (phosphenes, blurring) and sensory disturbances (paresthesias, dysesthesias).

\section{Visual Field Assessment}

Pre- and postoperative confrontational field tests were performed by both the surgeon and a neurologist in all patients. The initial six patients underwent preoperative and postoperative formal visual field studies. Subsequently, visual field tests were no longer performed routinely, and no additional patients had visual complaints or deficits on examination that would have justified formal visual field mapping.

\section{RESULTS}

We reviewed 47 patients who underwent a total of 59 procedures.

\section{Baseline VEPs}

Pre-operative baseline VEPs obtained in a subset of 30 patients in this study have previously been reported (unpublished data). Responses were similar to those previously described,[3] with the N75 and P100 peaks (also termed peak III and IV) being identified most consistently. Significant prolongation of latencies of the N75 and P100 peaks compared to historical controls was noted. Average latencies for these two waves were approximately $100 \mathrm{msec}$ and $140 \mathrm{msec}$ respectively. Using binocular stimulation, the amplitude of the midline response $(\mathrm{Oz} / \mathrm{Cz})$ was typically larger, by 10 to $20 \%$, than either of the lateral responses, which themselves were symmetrical. Using monocular stimulation, the midline responses were also typically larger than the lateral responses. Symmetrical responses, lateralization ipsilateral to the stimulus, and lateralization contralateral to the stimulus were all observed. The waveform morphology and peak latencies did not differ significantly between preoperative baselines and 
intraoperative baselines (Fig. 1).

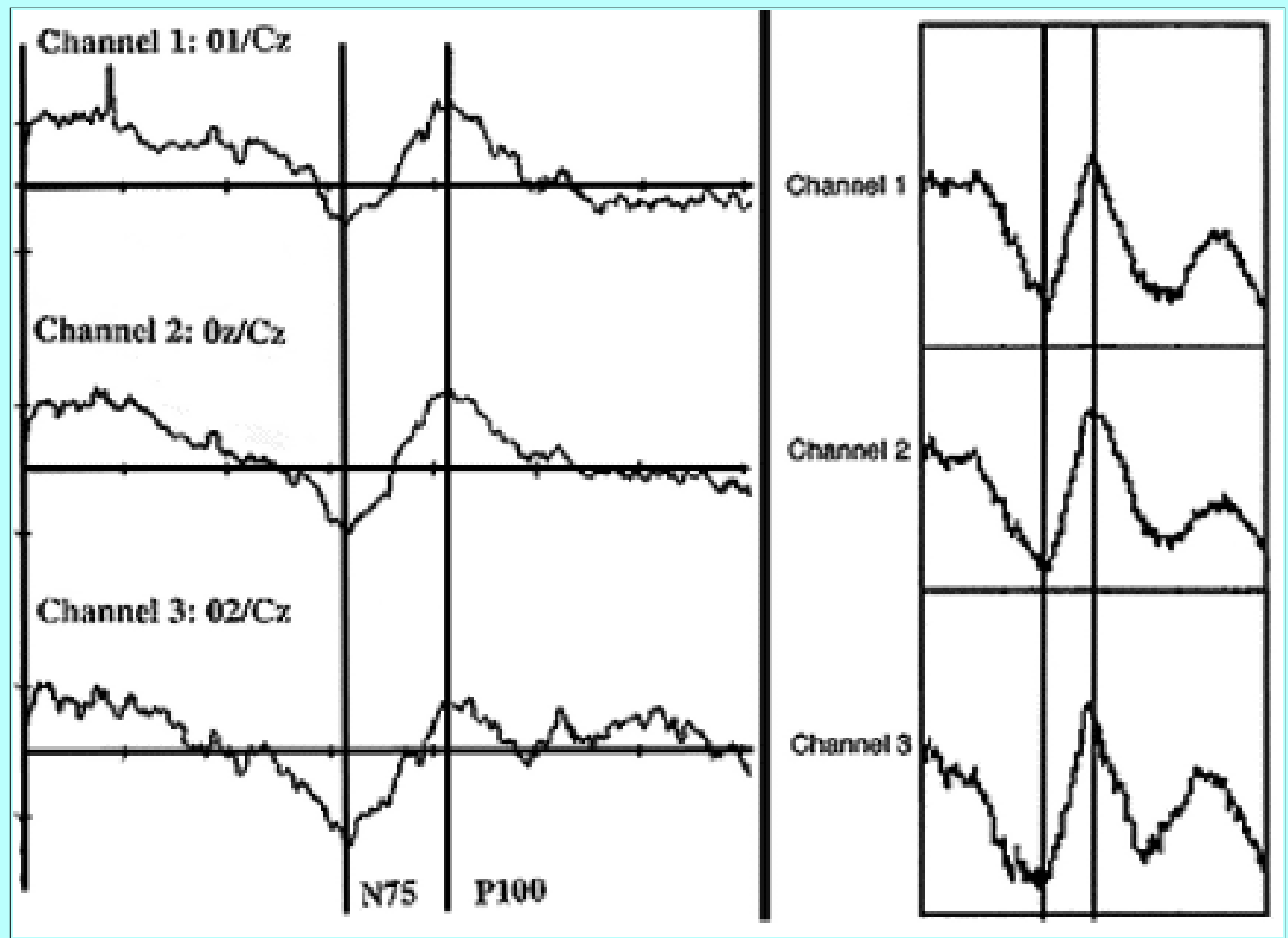

Fig. 1. Left: Baseline recordings of flash VEPs in a patient with PD obtained 1 day prior to surgery. An N75 peak and P100 peak (also termed peak III and IV) are consistently identified, and significantly delayed compared to normal subjects. Right: Baseline recordings of flash VEPs in the same patient, obtained in the operating room after sedation, frame placement, and MR imaging. Prior to surgical manipulation, wave morphologies and latencies are not significantly different from levels obtained 1 day before surgery.

\section{Intraoperative VEP Changes}

Visual evoked potentials were recorded reliably and reproducibly in all patients before surgical manipulation. In 48 procedures $(81 \%)$, variability in amplitude was less than $10 \%$, and latency shifts lasted less than $3 \mathrm{msec}$ throughout the entire operative procedure (Fig. 2 upper left). Operative times averaged 95 minutes (excluding stereotactic frame placement and imaging). The parameters monitored were the amplitudes and latencies of the N75 and P100 peaks, with amplitude reductions of $10 \%$ or more, and latency shifts of $3 \mathrm{msec}$ or more reported to the surgeon by the neurophysiologist. In 11 procedures (19\%), VEP changes were reported after stimulation, temporary lesioning, or permanent lesioning. These changes included six amplitude changes (10-80\%), six latency shifts (3-10 msec) and one report of "increased variability." Two patients showed both decreased amplitude and increased latency (Table 1, Fig. 2). 


\section{TABLE 1}

INTRAOPERATIYE YEP CHANGES *

\begin{tabular}{|c|c|c|c|c|c|c|c|c|c|}
\hline $\begin{array}{l}\text { Case } \\
\text { No. }\end{array}$ & $\begin{array}{c}\text { VEP } \\
\text { Change }\end{array}$ & Timing $S y$ & $\begin{array}{l}\text { Yisual } \\
\text { Symptorns }\end{array}$ & $\begin{array}{l}\text { Action } \\
\text { Taken }\end{array}$ & $\begin{array}{l}\text { VEP } \\
\text { Resut }\end{array}$ & $\begin{array}{l}\text { Yisual } \\
\text { Deficit }\end{array}$ & $\begin{array}{l}\text { Ope } \\
\text { Side }\end{array}$ & $\begin{array}{l}\text { Stimu- } \\
\text { lat ed }\end{array}$ & $\begin{array}{l}\text { Recorded } \\
\text { Changes }\end{array}$ \\
\hline 1 & dec amp $80 \%$ & stimulation & yes & $\begin{array}{l}\text { move } \\
1 \mathrm{~mm} \text { sup }\end{array}$ & resol ied & yes & $r t$ & $\mathrm{OD}$ & $\begin{array}{c}01 \mathrm{Cz}, \mathrm{Or} / \mathrm{Cz} \\
\mathrm{ORKz}\end{array}$ \\
\hline 2 & dec amp $30 \%$ & temp lesion & no & $\begin{array}{l}\text { move } \\
1 \mathrm{~mm} \text { sup }\end{array}$ & persisted & no & $r t$ & OS & $\underset{O 2 \mathrm{Cz}}{01 \mathrm{Cz}, \mathrm{Cz},}$ \\
\hline 3 & $\begin{array}{c}\text { dec amp } 20 \% \\
\text { inc latency } \\
10 \mathrm{msec}\end{array}$ & tem p lesion & no & $\begin{array}{l}\text { move } \\
1 \mathrm{~mm} \text { sup }\end{array}$ & im pro ved & no & $r t$ & OD & $\begin{array}{c}01 \mathrm{Cz}, \mathrm{Cr} / \mathrm{Cz} \\
\mathrm{Oegz}\end{array}$ \\
\hline 4 & $\begin{array}{c}\text { inc latency } \\
4 \mathrm{~m} \mathrm{sec}\end{array}$ & perm lesion & n no & none & persisted & no & $r t$ & $\begin{array}{c}\text { OD \& } \\
\text { OS }\end{array}$ & $\begin{array}{c}01 / \mathrm{Cz}, \mathrm{Gr} / \mathrm{Cz} \\
\mathrm{Oer} \mathrm{Cz}\end{array}$ \\
\hline 5 & $\begin{array}{l}\text { dec amp } 30 \% \\
\text { inc latency } \\
4 \text { m sec }\end{array}$ & tem p lesion & no & $\begin{array}{l}\text { move } \\
1 \mathrm{~mm} \text { sup }\end{array}$ & resol ied & no & It & $\begin{array}{c}\text { OS\& } \\
\text { OD }\end{array}$ & $\begin{array}{c}01 \mathrm{Cz}, \mathrm{Cr} / \mathrm{Cz} \\
\mathrm{OeKcz}\end{array}$ \\
\hline 6 & $\begin{array}{c}\text { inc latency } \\
3 \mathrm{~m} \mathrm{sec}\end{array}$ & perm lesion & no & none & resol ied & no & $r t$ & $\mathrm{OD}$ & $\underset{\mathrm{O} / \mathrm{Cz}}{01 \mathrm{Cz}, \mathrm{Cz}}$ \\
\hline 7 & $\begin{array}{l}\text { inc waria- } \\
\text { tility }\end{array}$ & perm lesion & no & none & resol ied & no & rt & OD & $\underset{O 2 / C z}{01 / C z}, \mathrm{Cz}_{1}$ \\
\hline 8 & $\begin{array}{c}\text { inc latency } \\
3 \mathrm{msec}\end{array}$ & perm lesion & n no & none & persisted & no & $\mathrm{rt}$ & $\mathrm{OD}$ & $\begin{array}{c}01 \mathrm{Cz}, \mathrm{Oz} / \mathrm{Cz} \\
02 \mathrm{Kz}\end{array}$ \\
\hline 9 & dec amp $10 \%$ & perm lesion & no no & none & persisted & no & rt & OS & $\underset{\mathrm{Oezz}}{01 \mathrm{Cz}, \mathrm{Cr}}$ \\
\hline 10 & $\begin{array}{c}\text { inc latency } \\
5 \mathrm{msec}\end{array}$ & perm lesion & no & none & resol ied & no & $\mathrm{rt}$ & OS & $\begin{array}{c}01 \mathrm{Cz}, \mathrm{Oz} / \mathrm{Cz} \\
0 \mathrm{~K} / \mathrm{Cz}\end{array}$ \\
\hline 11 & dec amp $40 \%$ & perm lesion & n no & none & resol ied & no & $r t$ & OS & $\underset{\mathrm{OeKz}}{01 \mathrm{Cz}, \mathrm{Cr}}$ \\
\hline
\end{tabular}

"Amp = amplitude; dec $=$ decreased; inc $=$ increased; perm = permanent; $\sup =$ superior; and temp $=$ tem porary. 


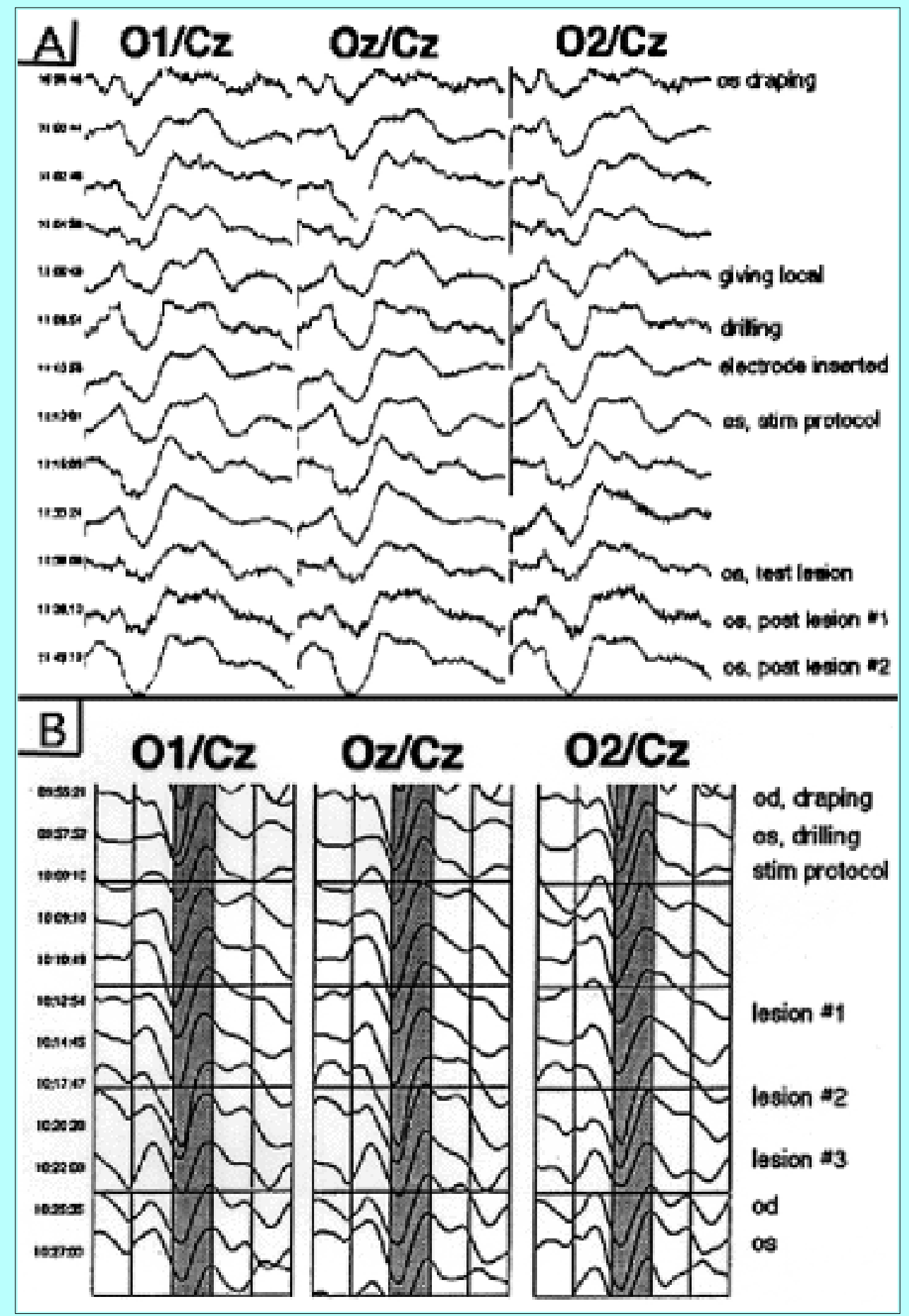

Fig. 2. Representative VEPs recorded during macroelectrode-based pallidotomy (filtered data, $200 \mathrm{msec}$ trace). A: Visual evoked potentials are unchanged throughout procedure. Such tracings are typical of $80 \%$ of patients. B: Visual evoked potentials showing increased latency bilaterally after a permanent lesion is made, which persisted throughout the procedure in Case 4. C: Visual evoked potentials showing decreased amplitude bilaterally with test lesioning. The probe was withdrawn $1 \mathrm{~mm}$ before permanent lesioning, and VEPs returned to baseline by the conclusion of procedure in Case 2. D: Intraoperative VEPs in a patient with a small postoperative quadrantanopsia showing transient amplitude reduction of $80 \%$ just after stimulation in Case 1 . The electrode was withdrawn $1 \mathrm{~mm}$ prior to permanent lesioning. 


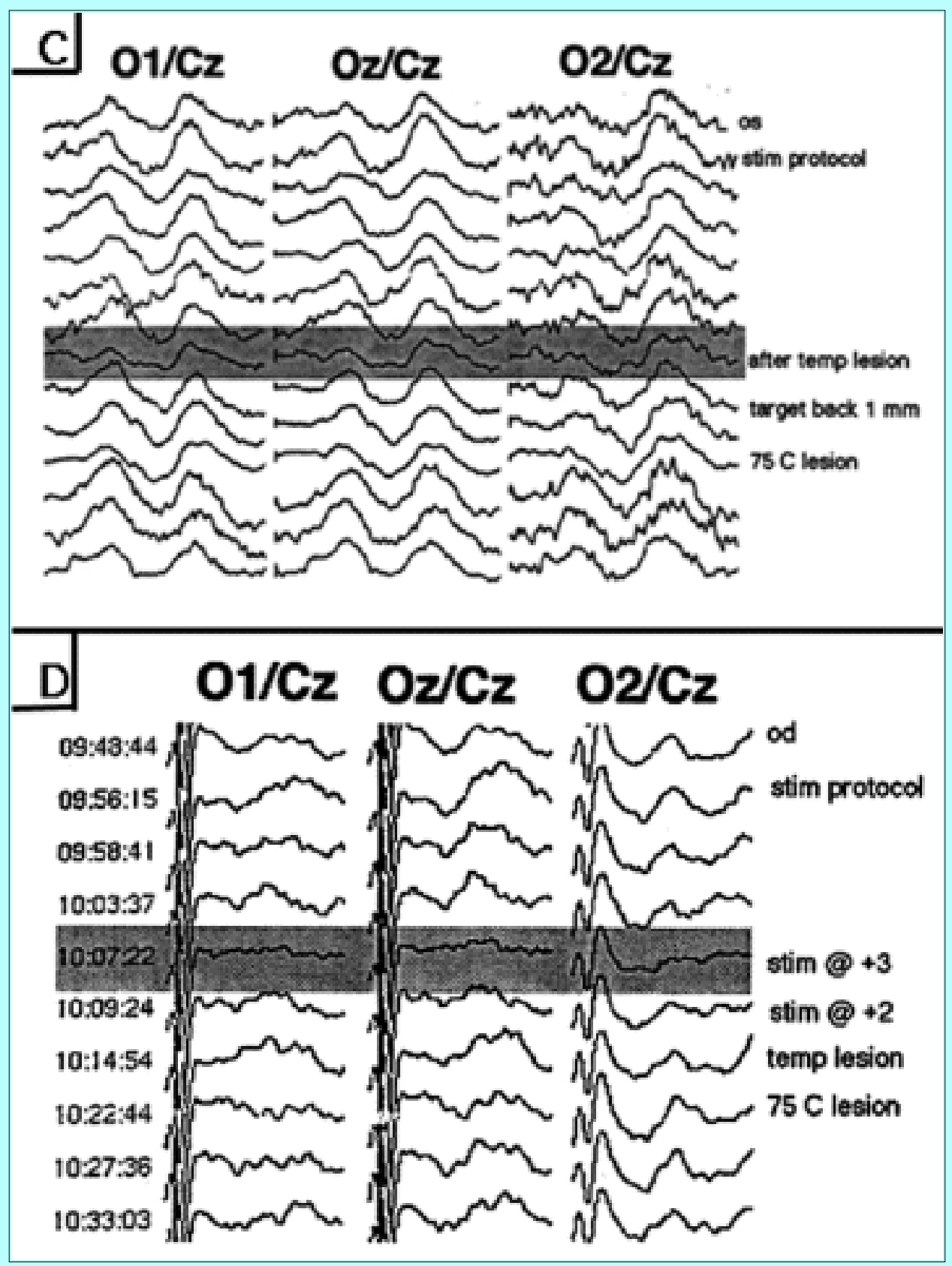

Visual symptoms accompanied the VEP changes in only one patient (Case 1). This patient described a "honeycomb" effect in his visual field, and he sustained an injury to the optic tract. One patient without VEP changes experienced "flashing blue lights." The target in this latter patient was moved $1 \mathrm{~mm}$ superiorly, and no visual deficit was present postoperatively. The dissociation between visual symptoms and electrophysiological changes has also been noted by Lozano, et al.[22]

In all cases, the intraoperative VEP changes occurred across all three recording channels $(\mathrm{O} 1 / \mathrm{Cz}, \mathrm{Oz} / \mathrm{Cz}$, and $\mathrm{O} 2 / \mathrm{Cz}$ ). In five of 11 cases, the change was detected during contralateral monocular stimulation, in four of 11 cases, during ipsilateral stimulation, and in two of 11 cases, the change was confirmed for both ipsilateral and contralateral stimulation. Ten of the eleven patients with VEP changes had undergone right-sided pallidotomies. In seven of 11 cases, the VEP changes resolved prior to the conclusion of the procedure, although in four of 11 cases, the VEP changes persisted.

In four patients (Cases 1, 2, 3, and 5), VEP changes prompted a change in electrode position. In Cases 3 and 5, changes occurred during temporary lesioning. The electrode was withdrawn $1 \mathrm{~mm}$ in the dorsal 
direction and the VEP changes resolved or improved. Additional testing prior to proceeding with permanent lesioning did not produce further VEP changes. In Case 2, VEP changes during performance of the test lesion likewise prompted a change in electrode position in the dorsal direction, but VEPs did not return to baseline. Additional testing prior to proceeding with permanent lesioning did not produce further VEP changes. None of these patients experienced visual morbidity.

In the single case (Case 1) with a postoperative visual deficit, visual symptoms were noted at the time of stimulation and a transient change in amplitude of $80 \%$ was noted (Fig. 2 lower right). The electrode was withdrawn $1 \mathrm{~mm}$, and VEP changes and symptoms could no longer be evoked with stimulation.

Permanent lesioning at the new target was completed. Formal visual field testing revealed a heteronymous superior quadrantanopsia (Fig. 3). Postoperative MR imaging at 7 months showed the proximity of the lesion to the optic tract (Fig. 4).

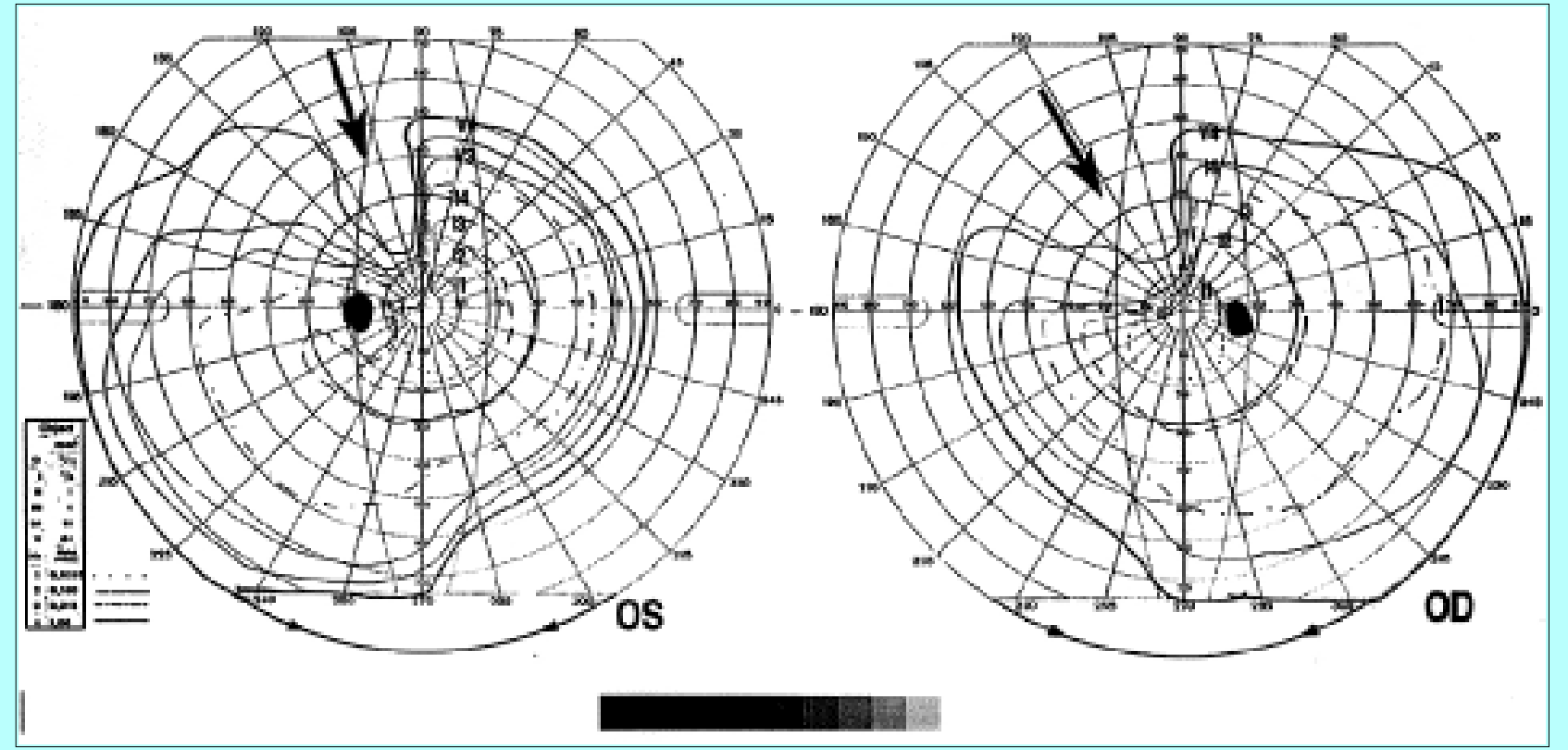

Fig. 3. Postoperative visual field test results in Case 1, showing a small superior quadrantanopsia. Preoperative visual fields were normal.

\section{Visual Morbidity}

The only confirmed visual deficit in this series was an asymptomatic superior quadrantanopsia present on formal field testing and detectable on detailed clinical examination (Case 1). This was the first patient in this series to undergo pallidotomy using intraoperative VEPs.

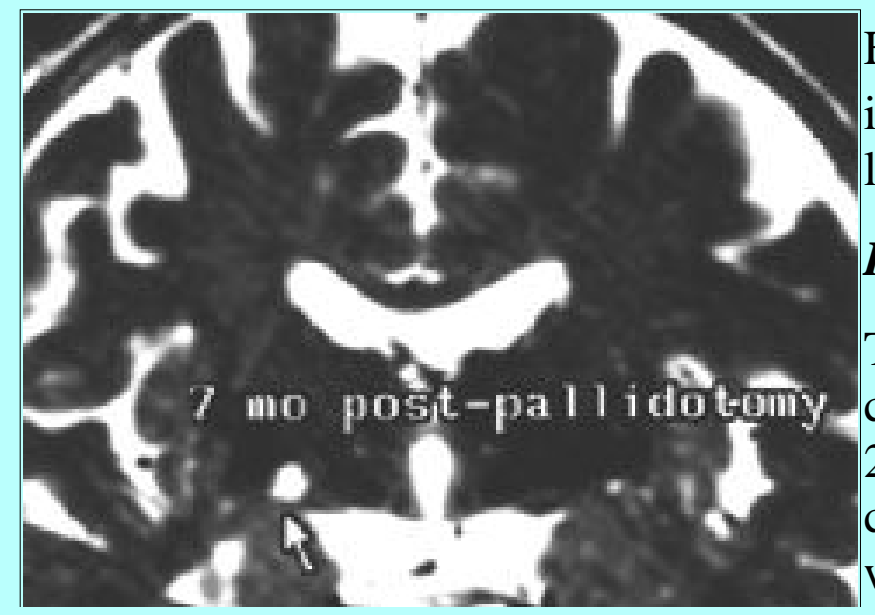

Fig. 4. Postoperative $\mathrm{T}_{2}$-weighted MR image obtained in Case 1 at 7 months showing proximity of the GPi lesion to the optic tract.

\section{Lesioning Parameters}

There were no significant differences in the mean lesion coordinates for the group with VEP changes (x coordinate, $20.6 \mathrm{~mm} \pm 0.9 \mathrm{SD} ; \mathrm{y}$ coordinate, $2.8 \mathrm{~mm} \pm 0.2 \mathrm{SD} ; \mathrm{z}$ coordinate, $-4.2 \mathrm{~mm} \pm 0.7 \mathrm{SD}$ ) compared to the group without (x coordinate, $20.9 \mathrm{~mm} \pm 0.9 \mathrm{SD}$; y coordinate, 2.4 


\section{Clinical Outcomes}

The detailed analysis of UPDRS scores in this group of patients is the subject of a forthcoming report. For the purposes of this report, outcome was ranked as excellent, good, or poor. An "excellent" outcome was defined as dramatic improvement in symptoms or functional gains, as reported by the patient and assessed by the neurologist; a "good" outcome was defined as modest improvement in symptoms; and a "poor" outcome as no improvement. No patient's condition was worse after pallidotomy. Overall for this group, $68 \%$ had an excellent outcome, $24 \%$ had a good outcome, and $8 \%$ had a poor outcome. To determine whether the target adjustments based on VEP changes had a detrimental effect on outcome, we assessed the outcomes of that subgroup of patients in whom target adjustments were made solely based on reported VEP changes. In those four patients, there was one excellent outcome, two good outcomes, and one poor outcome. This difference did not reach statistical significance (chi-square test $=4.8, \mathrm{p}=$ $0.09)$.

\section{DISCUSSION}

\section{Flash VEPs}

Flash VEPs have been used to avoid injury to the anterior optic pathways during parasellar surgery,[10,30] resection of chiasmal gliomas,[1] intraorbital surgery,[31] and endoscopic sinus surgery.[16] Although pattern-reversal evoked potentials are generally considered more sensitive than flash evoked responses,[24,28,29] we have found, as have others, that with current technology, the use of pattern reversal stimulation is impractical during surgical procedures. Furthermore the central 2 š of fovea is estimated to generate $65 \%$ of the pattern-reversal response;[5] flash stimuli, in contrast, tend to generate response from the peripheral retina as well. The purported insensitivity of flash VEPs, particularly in retrochiasmatic lesions, has been based on diagnostic studies in which patient recordings must differ from normative population data by 2 SDs to be considered abnormal. However, for intraoperative monitoring, comparisons are made on a minute-by-minute basis to the patient's own stable baseline data, and thus smaller changes due to acute injury may be more readily detected.

\section{Retrochiasmatic Lesions}

Visual evoked potentials have been used in the diagnosis of retrochiasmatic lesions using hemifield pattern stimulation, $[6,19,24,27]$ rather than full-field stimulation, to isolate the responses of each optic tract. Like pattern-reversal, the use of hemifield stimulation appears to be impractical during many neurosurgical procedures. Cedzich, et al.,[8] found two cases of occipital tumors in which postoperative visual deficits occurred with no intraoperative VEP change. However, such "false-negative" results have not been reported, to our knowledge, in lesions of the optic tract.

\section{Optic Tract Anatomy}

Although the retinotopic organization of the optic nerves has been well demonstrated, the organization of the optic tract is less well understood and is probably determined by retinotopic fiber order and morphological fiber class.[26] Nevertheless, the general pattern is still thought to be one in which fibers 
from the fovea course dorsally in the tract, fibers from the peripheral retina course through more ventral locations, fibers from the inferior retina are distributed medially, and those from the superior retina laterally.[7] Thus, as the optic tract is approached from the more lateral and superior GPi, injury to the lateral optic tract would produce a contralateral superior quadrantanopsia, as we saw in our Case 1. Baron and associates [5] reported one patient with a similar deficit. A more direct superior injury to the optic tract would produce macular defects, as described by Iacono, et al.[17] An inferior quadrantanopsia, as described by Laitinen and colleagues,[21] seems to be the most unlikely occurrence based on anatomical considerations. Because the input from each eye to the optic tract is not in exact retinotopic registration, visual field deficits are expected to be heteronymous, as in our patient.

\section{Pallidotomy and Visual Morbidity}

In the initial series of 42 pallidotomies performed by Laitinen and coworkers[21] using a macroelectrode technique, a 14\% incidence of homonymous hemianopsia was reported. With further experience, Laitinen[20] encountered no additional visual deficits in his next 100 reported patients. Dogali, et al.,[11] reported no visual morbidity in 18 patients undergoing pallidotomies with a microelectrode technique, whereas Baron and colleagues[4] noted a persistent superior quadrantanopsia in one $(6.7 \%)$ of 15 patients when they used similar techniques. Lozano, et al.,[22] used a combination of microstimulation and recording of strobe-evoked optic tract potentials to completely avoid optic tract injury in 27 patients. In Iacono and coworkers'[17] experience, using a combination of microelectrode and macroelectrode localization, three of 126 patients suffered partial pericentral (macular) hemianopsia. Although the best method for localization remains controversial, the evidence suggests that visual complications may be more frequent when macroelectrode techniques are used. This pilot study was undertaken with the goal of minimizing visual morbidity during macroelectrode pallidotomy by monitoring intraoperative VEPs.

\section{Visual Evoked Potential Changes During Pallidotomy}

In this series, VEPs were recorded reliably and reproducibly in awake patients undergoing pallidotomy, probably at least in part due to the lack of anesthetic- and metabolic-induced variability. In 11 of 59 procedures, VEP changes were noted, although only four of these changes led to target adjustments. The changes in all cases occurred within approximately 1 minute of surgical manipulation, corresponding to the time frame necessary to obtain a time-averaged epoch. Because the changes associated with stimulation and "test" lesioning are temporary, this time frame was sufficient to allow for adjustment of the target prior to further lesioning.

Intuitively, one might expect unilateral optic tract injury to affect the ipsilateral scalp recording preferentially. In our patients, changes appeared to be present to a similar degree in all three recording channels, making left-to-right comparisons less helpful. Symmetrically delayed occipital VEP responses after whole-field stimulation in unilateral retrochiasmatic lesions have also been described by others.[27] As compared to somatosensory evoked potentials, the generation of VEPs is a more complex phenomenon. A variety of pathways for visual information may be involved, including the retinogeniculostriate pathway, retinotectal pathway, and retinocerebellar pathways.[27] The "generators" of each portion of the response are distributed throughout various structures, [27] but at least in part are accounted for by the mesial surface of the occipital lobe.[9] This latter fact accounts for the sometimes observed paradoxical lateralization $[9,19]$ of the VEP response after hemifield stimulation and suggests that the optic tract contributes to the generation of both the ipsilateral and contralateral surface responses (despite the fact that the tract projects only to the ipsilateral occipital lobe). 
In this series, we encountered one false-negative VEP recording: that is, one in which VEPs were unchanged in an optic tract injury. In Case 1, the initial 80\% VEP amplitude reduction resolved and was not reproduced after electrode repositioning, yet the patient developed a visual field deficit. The proximity of the pallidal lesion to the optic tract on postoperative imaging (Fig. 4) suggests that a more significant visual field deficit would likely have resulted had target adjustments not been made. Thus VEPs were still helpful in this case.

In Cases 3 and 5, optic injury appears to have been averted with the aid of VEP monitoring, although false-positive VEP changes cannot be excluded. To determine if these cases represent false-positives, one would need to proceed with permanent lesioning despite the VEP changes. In Case 2, the VEP changes induced by temporary lesioning persisted through the end of the case. We opted to proceed with permanent lesioning after repositioning the electrode despite these persistent changes for two reasons. First, the $30 \%$ reduction in amplitude with preserved latency was a relatively minor change compared with Cases 1, 3, and 5. Furthermore, at the new target, we were unable to produce further changes in the VEP recordings with stimulation or test lesioning. Although Case 2 represents a false-positive, the initial adjustment in target coordinate may still have been appropriate to avoid optic tract injury.

In seven cases, VEP changes occurred after permanent lesioning that were not detected after stimulation or test lesioning. Most of these changes were transient, and none of these patients had visual deficits. Of importance, we did not consider these cases to be false-positives because the changes did not result in erroneous alteration of the lesion target. Permanent radiofrequency lesions may produce a transient neuropraxic dysfunction of the optic tract, and concomitant VEP changes, at a greater distance from the probe compared with the test lesions and stimulation protocol. In the absence of VEP changes during stimulation or test lesioning, VEP changes following permanent lesioning do appear to predict optic tract injury.

Based on this small number of patients, changes in VEP amplitude of greater than $10 \%$ or latency shifts longer than $3 \mathrm{msec}$ occurring during stimulation or test lesioning under the conditions described indicate a need for target adjustment. Raising the threshold for amplitude changes to between $30 \%$ and $40 \%$ might increase the specificity of the test, at the risk of decreasing sensitivity. Although this would have been a more powerful study had we obtained preoperative and postoperative visual field testing in all patients, we could not justify the expense of routine testing. Furthermore, our endpoint of "clinically significant" visual field deficits may be more appropriate. Finally, the lack of visual morbidity in this series cannot be entirely attributed to the use of VEPs and may be a result of improved neuroimaging and target localization or a result of the small volume of tissue lesioned relative to other series.

\section{CONCLUSIONS}

Visual evoked potentials can be recorded easily, safely, and reliably during procedures performed in the awake patient. This is aided by the lack of variability induced by anesthetics and other metabolic changes. The $1.7 \%$ visual morbidity rate reported here using macroelectrodes and VEPs compares favorably with other series in which microelectrodes were used. Although the low incidence of visual morbidity cannot be complete ascribed to the use of VEPs, this preliminary reports suggests that the technique may be useful to reduce the incidence of clinically significant visual morbidity during pallidotomy, especially during formal lesioning of the ventral pallidum close to the optic tract. More detailed study will be required to define the role of VEPs during macroelectrode-based pallidotomy. 


\section{References}

1. Albright AL, Sclabassi RJ: Cavitron ultrasonic surgical aspirator and visual evoked potential monitoring for chiasmal gliomas in children. Report of two cases. J Neurosurg 63:138-140, 1985

2. Allen A, Starr A, Nudleman K: Assessment of sensory function in the operating room utilizing cerebral evoked potentials: a study of fifty-six surgically anesthetized patients. Clin Neurosurg 28:457-481, 1981

3. Aminoff MJ, Goodin DS. Visual evoked potentials. J Clin Neurophysiol 11:493-499, 1994

4. Baron MS, Vitek JL, Bakay RE, et al: Treatment of advanced Parkinson's disease by posterior GPi pallidotomy: 1-year results of a pilot study. Ann Neurol 40:355-366, 1996

5. Berson EL: Visual function testing: clinical correlations. J Clin Neurophysiol 11:472-481, 1994

6. Brigell MG, Celesia GG, Salvi F, et al: Topographic mapping of electrophysiologic measures in patients with homonymous hemianopia. Neurology 40:1566-1570, 1990

7. Brodal A: Neurological Anatomy. In Relation to Clinical Medicine, ed 3. New York: Oxford University Press, 1981, pp 578-601

8. Cedzich C, Schramm J, Fahlbusch R: Are flash-evoked visual potentials useful for intraoperative monitoring of visual pathway function? Neurosurgery 21:709-715, 1987

9. Celesia GG: Correlation between visual evoked potentials and PET neuro-imaging in subjects with retrochiasmatic lesions. EEG Clin Neurophys 39 (Suppl):276-280, 1987

10. Costa e Silva I, Wang AD, Symon L: The application of flash visual evoked potentials during operations on the anterior visual pathways. Neurol Res 7:11-16, 1985

11. Dogali M, Fazzini E, Kolodny E, et al: Stereotactic ventral pallidotomy for Parkinson's disease. Neurology 45:753-761, 1995

12. Feinsod M, Selhorst JB, Hoyt WF, et al: Monitoring optic nerve function during craniotomy. J Neurosurg 44:29-31, 1976

13. Fisher RS, Raudzens P, Nunemacher M: Efficacy of intraoperative neurophysiological monitoring. J Clin Neurophysiol 12:97-109, 1995

14. Goetz CG, Diederich NJ: There is a renaissance of interest in pallidotomy for Parkinson's disease. Nature Med 2:510-514, 1996

15. Hahn JF, Latchaw JP: Evoked potentials in the operating room. Clin Neurosurg 31:389-403, 1983

16. Herzon GD, Zealear DL: Intraoperative monitoring of the visual evoked potential during endoscopic sinus surgery. Otolaryngol Head Neck Surg 111:575-579, 1994

17. Iacono RP, Shima F, Lonser RR, et al: The results, indications, and physiology of posteroventral pallidotomy for patients with Parkinson's disease. Neurosurgery 36:1118-1127, 1995

18. Kondziolka D, Bonaroti EA, Lunsford LD: Pallidotomy for Parkinson's disease. Contemp 
Neurosurg 18:1-7, 1996

19. Kuroiwa Y, Celesia GG. Visual evoked potentials with hemifield pattern stimulation. Their use in the diagnosis of retrochiasmatic lesions. Arch Neurol 38:86-90, 1981

20. Laitinen LV: Pallidotomy for Parkinson's disease. Neurosurg Clin North Am 6:105-112, 1995

21. Laitinen LV, Bergenheim AT, Hariz MI: Leksell's posteroventral pallidotomy in the treatment of Parkinson's disease. J Neurosurg 76:53-61, 1992

22. Lozano A, Hutchison W, Kiss Z, et al: Methods for microelectrode-guided posteroventral pallidotomy. J Neurosurg 84:194-202, 1996

23. Lozano AM, Lang AE, Glavez-Jimenez N, et al: Effect of GPi pallidotomy on motor function in Parkinson's disease. Lancet 346:1383-1387, 1995

24. Onofrio BM, Bodis-Wollner I, Mylin L: Visual evoked potential diagnosis of field defects in patients with chiasmatic and retrochiasmatic lesions. J Neurol Neurosurg Psychiatry 45:294-302, 1982

25. Raudzens PA: Intraoperative monitoring of evoked potentials. Ann NY Acad Sci 388:308-326, 1982 26. Reese BE: Clinical implications of the fibre order in the optic pathway of primates. Neurol Res 15:83-86, 1993

27. Samson-Dollfus D, Parain D, Weber J, et al: The visually evoked potential in retrochiasmatic lesions of the optic pathways: an attempt to interpret the responses obtained by flash pattern stimulation and the results of the calculation of the correlation coefficient between visually evoked potenials. Adv Neurol 32:71-80, 1982

28. Symon L, Momma F, Schwerdtfeger K, et al: Evoked potential monitoring in neurosurgical practice. Adv Tech Stand Neurosurg 14:25-70, 1986

29. Wenzel D, Brandl U, Beck JD, et al: Visual evoked potentials in tumors from orbita to occipital lobe in childhood. Neurosurg Rev 11:279-286, 1988

30. Wilson WB, Kirsch WM, Neville H, et al: Monitoring of visual function during parasellar surgery. Surg Neurol 5:323-329, 1976

31. Wright JE, Arden G, Jones BR: Continuous monitoring of the visually evoked response during intra-orbital surgery. Trans Ophthalmol Soc UK 93:311-314, 1973

32. Zaaroor M, Pratt H, Feinsod M, et al: Real-time monitoring of visual evoked potentials. Israel J Med Sci 29:17-22, 1993

Manuscript received January 24, 1997.

Accepted in final form February 21, 1997.

Address reprint requests to: Eugene A. Bonaroti, M.D., University of Pittsburgh School of Medicine, B400 Presbyterian University Hospital, 200 Lothrop Street, Pittsburgh, Pennsylvania 15213. email: bonaroti@np.awing.upmc.edu 